\title{
Effecient Photo-Stabilizers: By Using Medications As Ligands Connected to Oragontin(IV) Complexes
}

\author{
Emad Alhaydary and Emad Yousif*
}

Department of Chemistry, College of Science, Al-Nahrain University, Baghdad, Iraq

\begin{tabular}{ll}
\hline \multicolumn{1}{c}{ Article's Information } & \multicolumn{1}{c}{ Abstract } \\
\hline Received: & Organotin materials have several applications in industry and medicine since it \\
06.06 .2021 & uses to prepare medications. Moreover, it is used as photo-stabilizers for different \\
Accepted: & plastic polymers such as polyvinyl chloride, polystyrene, and polyvinyl alcohol. \\
10.09 .2021 & Herein, it is going to focus on one application which is utilizing organotin \\
Published: & complexes as photo-stabilizers of polyvinyl chloride. Since organotin (IV) can \\
30.09 .2021 & easily obtained by oxidizing organotin (II) that is more stable. Organotin (IV) can \\
\hline Keywords: & be designed in different forms depending on the number of organic and anion \\
Drugs & groups connected to the tin such as mono-organotin, di-, tri- and tetra- \\
PVC & compounds. There are several applications of organotin materials in both \\
Organotin (IV) & industrial and medicine areas and in this paper, we are going to study some of a \\
Plastic polymers & significant photo-stabilizers and their applications and we are going to highlight \\
Photo-stabilizers & the using of organotin materials as photo-stabilizers of plastic polymers especially \\
Photo-degradation & the PVC polymeric films.
\end{tabular}

DOI: 10.22401/ANJS.24.3.04

*Corresponding author: emad_yousif@hotmail.com

\section{Introduction}

\section{Some applications of organotin materials}

Organotin materials have different uses in several areas such as in biology, medicine and industry. The most known industrial application is using them as stabilizers of PVC, and plasticization of polymeric silicone [1]. Thus, organotin materials have been also used as anticancer and antibacterial medications in medicine area [2]. In biology, these compounds were used as paints for boats to prevent the bacteria and fungi from attacking the boat wood and decompose it [3]. Herein we are going to describe the using of organotin materials as photo-stabilizers of PVC and review the major significant research papers regarding that.

\section{Photo-degradation of PVC polymeric chains}

Poly(vinyl chloride) or PVC is the third largest plastic polymer consumed around the world after polypropylene and polyethylene. Hence every year about 40 million tons are produced of it $[4,5]$. There are two main forms of PVC rigid and flexible. These unique properties of PVC make it suitable for many outdoor and indoor applications such as windows, doors, making bottles, packaging, etc. Flexible PVC can be used as an insulator of electrical cables, plumbing, flooring, and several other applications [6,7]. Pure PVC is insoluble in methanol or ethanol but soluble in THF and it is a bright white solid power with a molecular formula $\left(\mathrm{C}_{2} \mathrm{H}_{3} \mathrm{Cl}\right)_{\mathrm{n}}$ as shown in Figure 1.

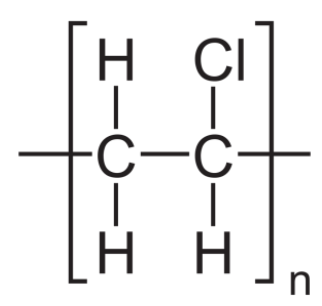

(a)

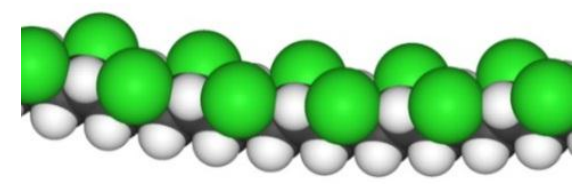

(b)

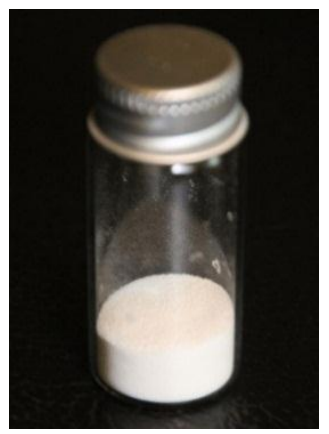

(c)

Figure 1. (a) PVC chemical structure; (b) Module of PVC chain; (c) Pure PVC in a little jar without additives. 


\section{Al-Nahrain Journal of Science}

ANJS, Vol.24 (3), September, 2021, pp. 23-29

\begin{abstract}
Although with all the positive properties of PVC but still there are deficiencies such as the degradation of PVC polymeric chain after exposure to sunlight or UV light by discoloration of chlorine atom by releasing $\mathrm{HCl}$ molecules via elimination reaction and changing the properties of the polymer, this phenomenon also called yellowing. Another mechanism of photo-degradation is by oxidative decomposition of PVC chains in the presence of oxygen under UV light. Figure 2 shows an example of photodegradation of plastic bottle has remain under sunlight for a long time.
\end{abstract}

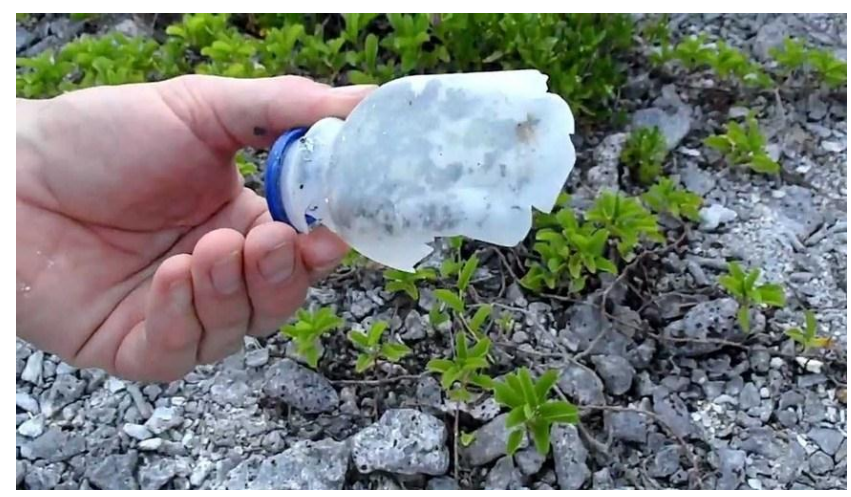

Figure 2. Photo-degradation photo of PVC plastic polymer.

Therefore, it is very hard to use PVC without any additives (stabilizers or photo-stabilizers) [8-11]. The main properties should be available in the stabilizers are absorption of UV light, cheap, easy to form, not toxic and very good merged with polymer chains. Moreover, the stabilizers should not be volatile, changing the color of PVC and the most important point that the additive should not cause pollution to environment by itself and harm the ecosystem. The major additives of PVC work as thermal stabilizers, flame retardants, scavengers of free radicals, and photo-stabilizers [12-14]. PVC photo-stabilizers are divided into two main types the first one is primary photo-stabilizers which works as de-activator of allylic chloride. This compound is form during the photo-degradation of polymeric chains. The second type is secondary photostabilizers which work as scavengers of chlorine free radicals that formed because of photo-degradation [15].

Different approaches have been applied by researchers to control the formation of double bonds within the polymer structure such as FTIR, UV, Rama, and NMR spectroscopies. In photo-degradation process, first hydrochlorides molecules released to form not double bond but allylic structure and the terminal double bonds are quickly oxidized to ketones in the existence of oxygen forming keto-allylic units. This degradation happens when the polymer exposure to UV light under $200 \mathrm{~nm}$ [16]. The photo-degradation sometimes leads to the cleavage of polymer chains or makes crosslinking within the polymer chains look Scheme 1 below [17-20].
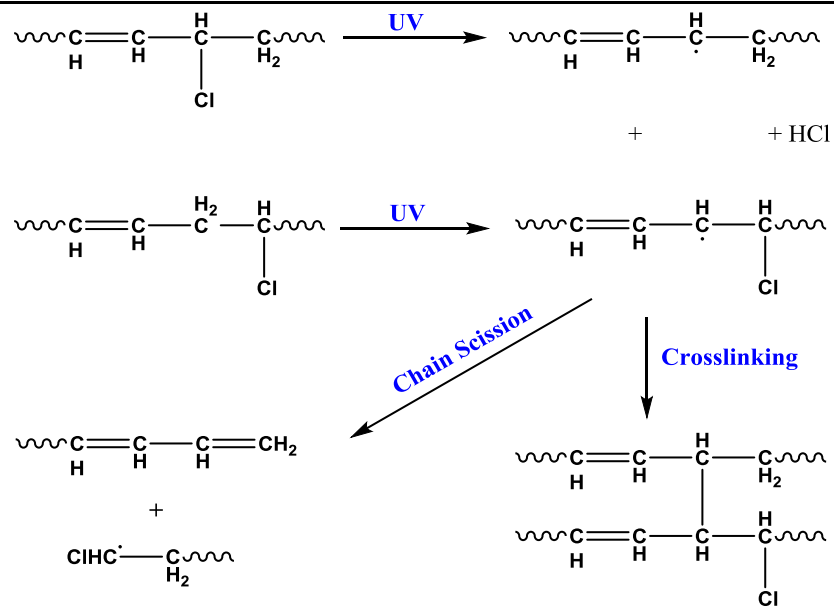

Scheme 1. Proposed mechanism of PVC photo-degradation [17].

However, the formed keto-groups can undergo two photochemical reactions. Number one is Norrish I or $\alpha$ cleavage which releases carbon monoxide gas and forms free radicals on the end of polymeric structure. The second reaction is Norrish II which involves the formation of intermediate six membered rings which leads to formation of ketones and olefin structures after several re-arrangement reactions as shown in Scheme 2 below [21].

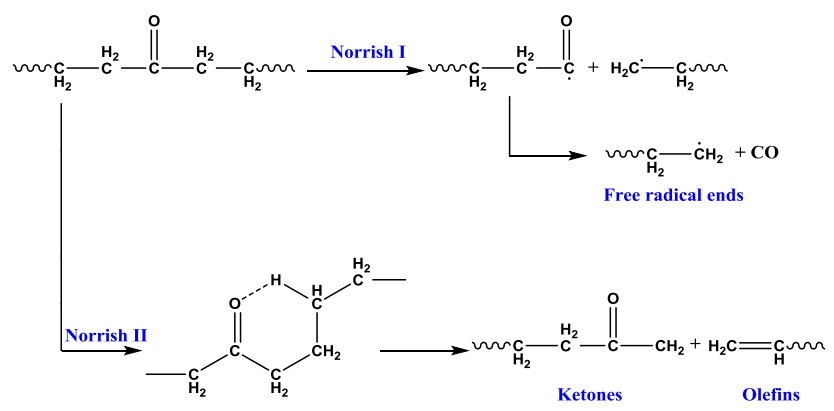

Scheme 2. Norrish reaction I and Norrish reaction II [20].

From all above, we can say that photo-degradation is an unfavorable process in all applications of PVC polymeric materials [22]. This is because photo-degradation results in the alternations of chemical and physical properties of the polymer and losing several important features. For example, photo-degradation can cause reducing the molecular weight of the polymer, changing the surface morphology, and changing the chemical structure of it [23-25]. The existence of this damage can be reduced by using special types of photo-stabilizers [26] as shown in Figure 3 and the most important types are organotin photo-stabilizers as will be reviewed in next sections [27]. 


\section{Al-Nahrain Journal of Science}

ANJS, Vol.24 (3), September, 2021, pp. 23-29
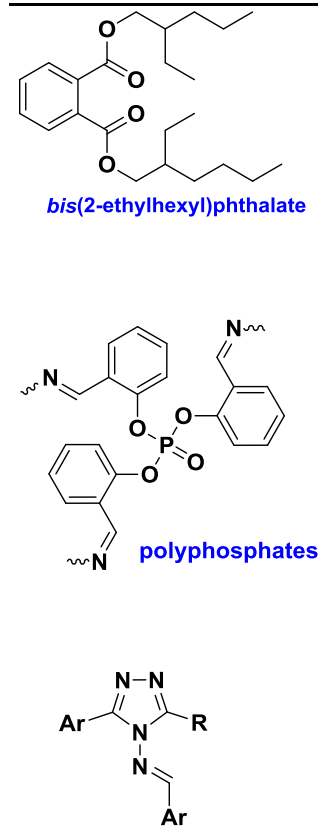

aryl Schiff bases
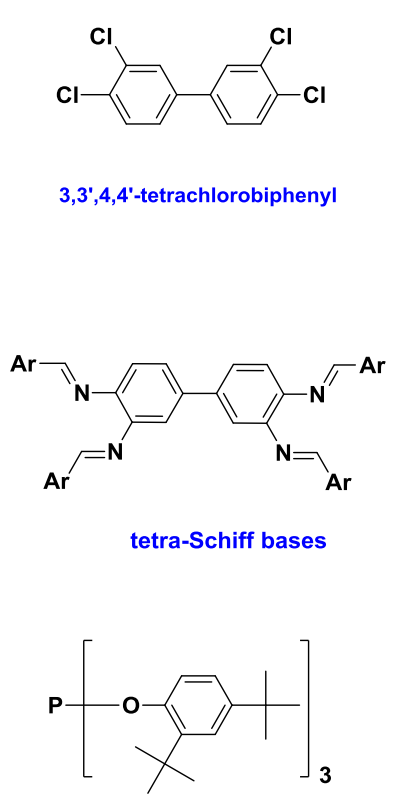

tris(2,4-di-tert-butylphenyl)phosphite

Figure 3. Chemical structures of most famous PVC photostabilizers.

\section{Using Organotin materials as Photo-stabilizers of PVC}

Since 1940, organotin materials were used as photostabilizers of PVC to stop the photo-degradation [28]. Although, the first successful commercial photo-stabilizers were made in 1984 by Ayrey et al. When they published their paper in polymer additives journal. They are dibutyltin methyl maleate, dibutyltin dilaurate, and dibutyltin maleate [29] as shown in Figure 4. Normally the photo-stabilizer is used with percentage between $0.2-3 \%$ by weight related to the polymer. Choosing the suitable stabilizers and determining the amount of stabilizer are depending on the polymer application, how the stabilizer can work in shortterm during the process also in long-term in the using, and delaying the yellowing phenomenon [30].
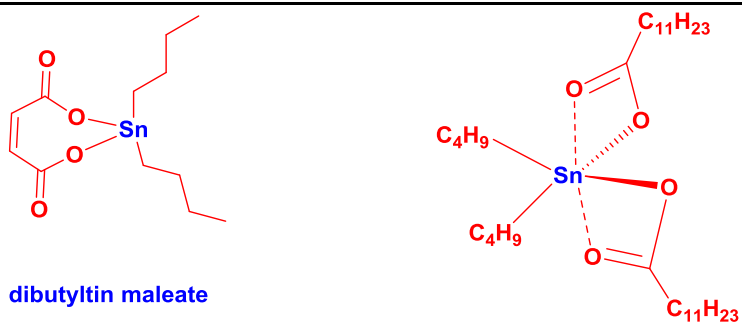

dibutyltin dilaurate

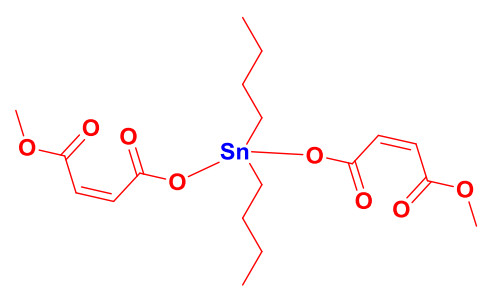

dibutyltin methyl maleate

Figure 4. Chemical structure of most common di-organotin photo-stabilizers.

Generally, the tetravalent (IV) tin is used as photostabilizers of PVC compounds. Thus, the properties of stabilizers influence by the nature of ligand linkage to tin and as well to the ratio of molecules to tin. The toxicological features of formed compound can be exhibited depending on the linkage between carbon-tin bonds. However, this linkage has no effect of working the molecule as photostabilizer [31]. The responsible part of photo-stabilization is the linkage of tin with oxygen such as carboxylate organotin units or with sulfur such as mercaptide organotin moieties. Usually this part of the unit is determined the photostabilizer behavior during the process and after the usage [32].

Figure 5 shows the chemical structure of organotin (IV) photo-stabilizer has been recently used. Hence R is methyl, butyl or phenyl and benzamidoglycin is the ligand linkage to tin. The outcomes demonstrated the efficiency of this triorganotin (IV) complexes to reduce the photo-degradation of PVC after exposure to UV light. The study shows that the best results was get when $\mathrm{R}=$ phenyl group depending on the polyene and carbonyl groups formations. This is because phenyl groups absorb light at UV region which leads to protect the polymer chains from these harm waves [33].

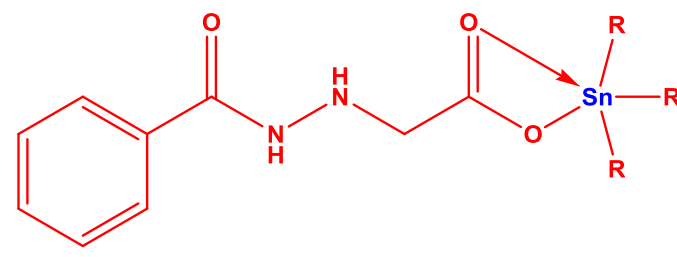

\section{$\mathbf{R}=$ Me, $\mathbf{n B u}$ or $\mathbf{P h}$}

Figure 5. Chemical structure of tri-organotin (IV) complex using benzamidoglycin as a ligand [34]. 


\section{Al-Nahrain Journal of Science}

ANJS, Vol.24 (3), September, 2021, pp. 23-29

$\mathrm{R}_{n} \mathrm{SnL}_{4-\mathrm{n}}$ is the general formula of organotin (IV) compounds which utilize as PVC photo-stabilizers. Hence $\mathrm{L}$ is an organic molecule (sometimes medications) and $\mathrm{R}$ is methyl, butyl or phenyl groups. Figure 6 shows an example of di-organotin compound where $\mathrm{L}$ is a naproxen which works as a co-photo-stabilizer because it can absorb at UV region as recent studies showed [35]. Naproxen is a medication which is determined as an anti-inflammatory medication. It is also used as pain killer for different condition for example toothache, headache, etc. These photo-stabilizers showed an excellent performance to reduce the photo-degradation of PVC polymer when mixed only $0.5 \%$ of it by polymer weight and after exposure to UV light at $313 \mathrm{~nm}$. Interestingly, dimethyltin (IV) naproxen complex shows the best result among other stabilizers. The reason of that is not very clear yet because logically diphenyltin (IV) naproxen complex should give the best result due to phenyl groups absorb light at UV region. However steric hindrance might have some influence regarding that [36].

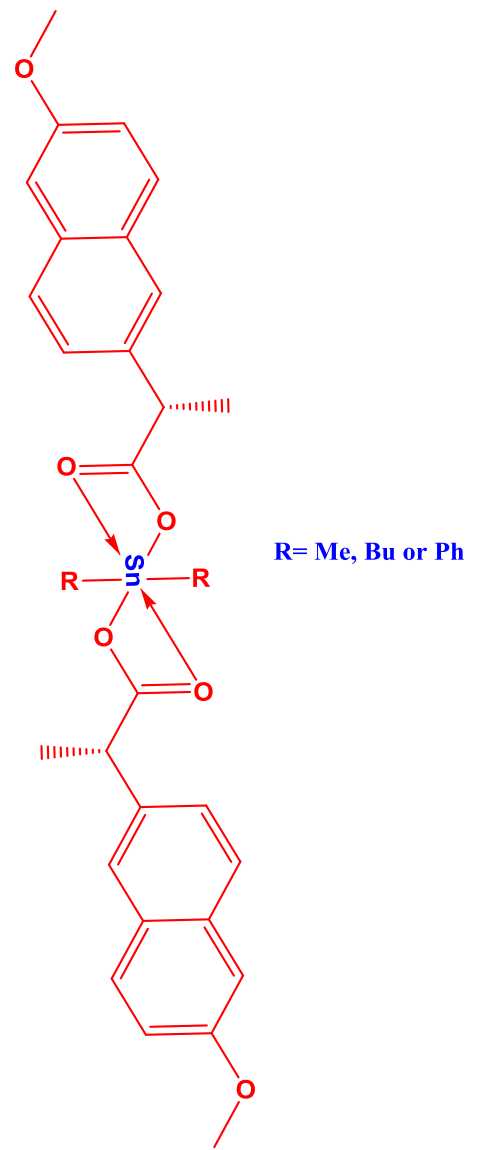

Figure 6. Chemical structure of di-organotin (IV) naproxen complexes [58].

Several mechanisms have be proposed that how organotin (IV) complexes work as heat and photostabilizers as shown in Scheme 3 after it has demonstrated them as very good UV-stabilizers. Organotin (IV) works as scavengers of $\mathrm{HCl}$ molecules by substitution the chlorine atoms in the PVC backbone due to Sn (IV) is a strong Lewis acid [37]. This procedure will stop the de-hydrochlorination process which leads to prevent the formation of alkene groups. The other process is called secondary photostabilization of PVC polymeric films by using $\mathrm{POOH}$ (hydro-peroxide) as decomposer. Thus, the Sn (IV) complexes could react and decompose the peroxides that will reduce the PVC photo-degradations [38]. The organotin (IV) containing conjugation system can work as free radical quenchers (POO) via making a complex between the stabilizer and radicals [39]. All above suggested mechanisms are described in Scheme 3.

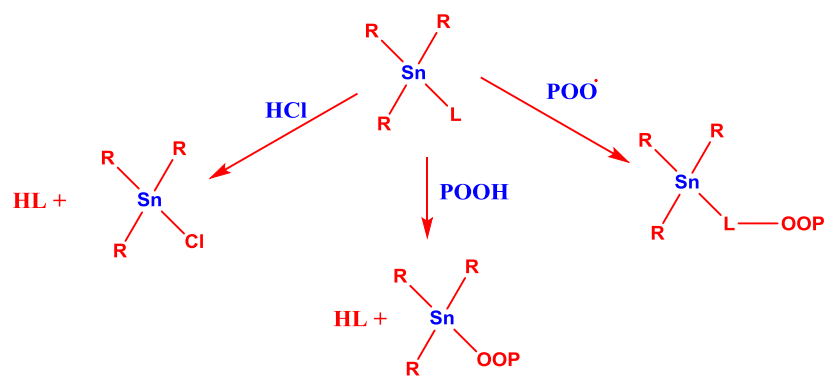

Scheme 3: Proposed mechanisms of stabilization PVC by using tri-organotin (IV) complexes [39].

In 2009, Hameed group has studied tri-organotin (IV) complexes as photo-stabilizers of PVC [40]. Again, they have used methyl, butyl and phenyl as R groups linked to tin atom and they have utilized benzamido methionine as $\mathrm{L}$ group see Figure 7. Different techniques, they applied to confirm the chemical structure of the product such as FTIR, ${ }^{1} \mathrm{H}$ NMR, and ${ }^{13} \mathrm{C}$ NMR. The product showed a significant result as photo-stabilizer to stop the photo-degradation of the polymer.

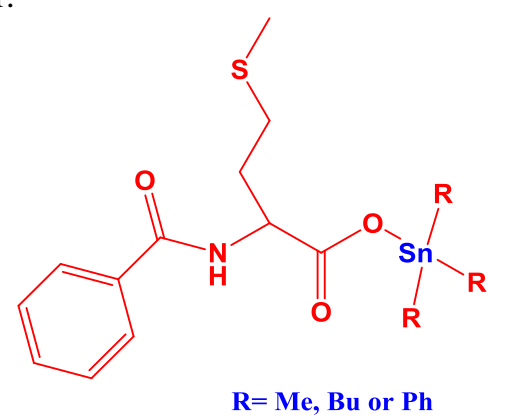

Figure 7. Chemical structure of Benzamidomethionine complexes as Tri-organotin (IV) complexes [40].

Another example of tri-organotin complexes were investigated by Yousif et. al in 2013, they were triorganotin(IV) with benzamido glycin as ligand [41]. The ligand was synthesized by reaction of glycin with benzoyl chloride in the existence of strong base. Nuclear magnetic resonance such as ${ }^{1} \mathrm{H}$ NMR, ${ }^{13} \mathrm{C}$ NMR and ${ }^{119} \mathrm{Sn}$ NMR with other techniques (FTIR, and elemental analysis) were utilized to characterized the structure of both prepared ligand and complexes. For complexes chemical structures see Figure 8 . The research has studied the photo-stability of PVC polymeric films mixed with $0.5 \%$ of tri-organotin (IV) 


\section{Al-Nahrain Journal of Science}

ANJS, Vol.24 (3), September, 2021, pp. 23-29

complexes after irradiation by UV light. The results exhibit that all prepared stabilizers showed an excellent behave against photo-degradation of polymeric films. The best result was gotten as expected for $\mathrm{Ph}_{3} \mathrm{SnL}$ then $\mathrm{Bu}_{3} \mathrm{SnL}$ and finally $\mathrm{Me}_{3} \mathrm{SnL}$. In this study the change in the molecular weight during irradiation time was also tracked by measuring the viscosity of the polymer.<smiles>[R][Sn]([R])([R])OC(=O)CNC(=O)c1ccccc1</smiles>

Figure 8. Chemical structure of Benzamidoglycin complexes as Tri-organotin (IV) complexes [41-43].

In 2016, the same above group has studied new diorganotin (IV) complexes by using benzamidoleucine as a ligand to stabilize the PVC polymeric films [44-45]. It was also used $0.5 \%$ of photo-stabilizer per polymer weight. The stability of blend polymeric films was tested by monitoring the formation of polyene, hydroxyl and carbonyl groups after exposure to UV light. The decreasing of polymer molecular weight during irradiation was also determined using viscosity method. The researchers were also calculated the chain scission quantum yield of blend polymeric films and it is found $5.77 \times 10^{-8}$ to $7.26 \times 10^{-8}$. The outcomes of this work demonstrated that all prepared complexes act as photo-stabilizers of PVC following the trend:

$\mathrm{Ph}_{2} \mathrm{SnL}_{2}>\mathrm{Bu}_{2} \mathrm{SnL}_{2}>\mathrm{Me}_{2} \mathrm{SnL}_{2}$

Figure 9 and Scheme 4 show suggested mechanism of PVC photo-stabilization by synthesized additives. It shows that these stabilizers protect the PVC from photodegradation by $\mathrm{UV}$ absorption, $\mathrm{HCl}$ scavengers, and peroxide decomposer depending on the structure of the additives.

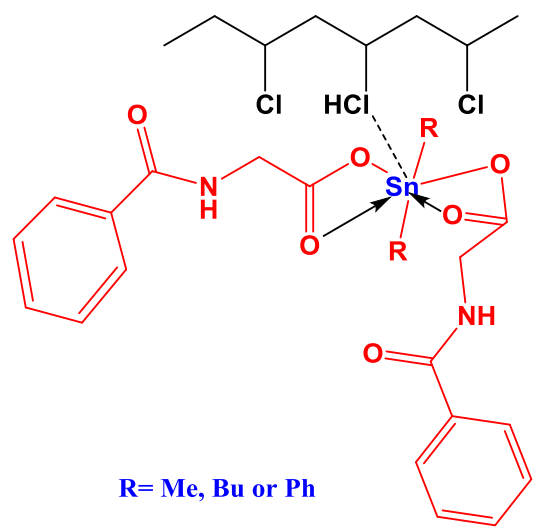

Figure 9. Proposed mechanism of PVC photo-stabilization by di-organotin benzamidoleucine complexes as primary stabilizers [42].

Before methyltin complexes were presented as photostabilizers, butyltin complexes were used as plastic stabilizers. However, nowadays the most consumed organotin in Europe as photo-stabilizers are octyltin and butyltin. While methyltin complexes are widely use in North America due to the low cost of synthesis.

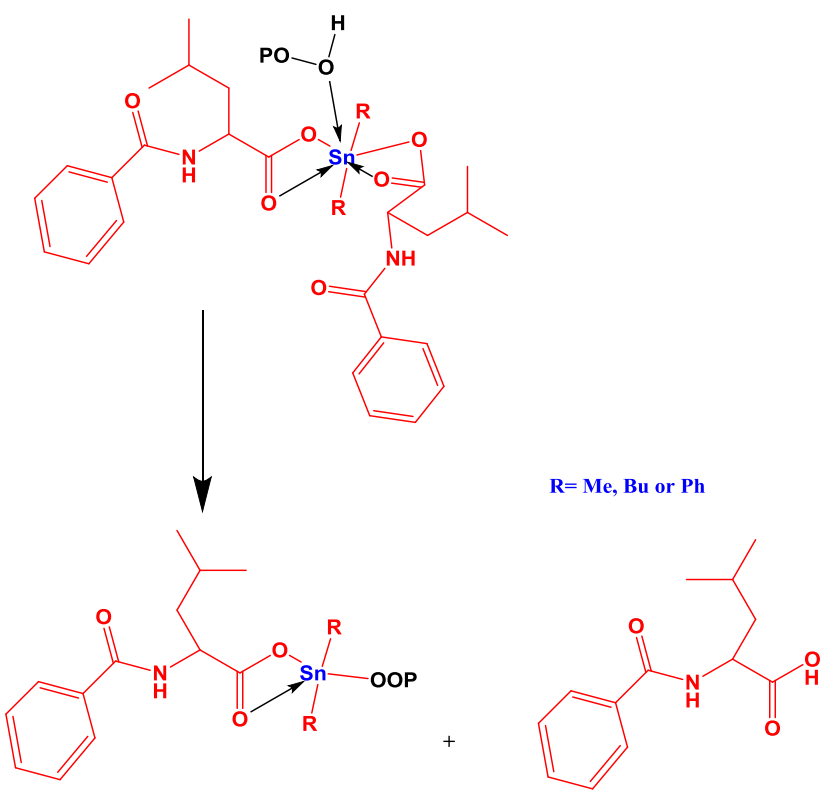

Scheme 4. Proposed mechanism of PVC photo-stabilization by di-organotin benzamidoleucine complexes as peroxide decomposer [42].

\section{Conclusion}

As has been presented in our short review about using organotin (IV) as photo-stabilizers of PVC materials so many good results have been achieved. Thus, the researchers are still working to synthesis and design new photo-stabilizer to reach an excellent efficiency, especially in large commercial scales. Up to date writing this report, there were only few authors have reported using medications as a ligand with organotin complexes. Herein we are introducing new organotin photo-stabilizers with using sulfamethoxazole drug as a ligand. Sulfamethoxazole is used as antibiotic against bacterial infections for example E. coli and Listeria. Yet nobody has utilized this drug to prepare organotin materials as PVC photo-stabilizer. Therefore, this paper recommends the researchers to investigate this drug as photo-stabilizer.

\section{Acknowledgments}

This project is supported by Al-Nahrain University.

\section{Conflicts of Interest}

The authors declare no conflict of interest.

\section{References}

[1] Ahmed D.S.; El-Hiti G.A.; Hameed A.S.; Yousif E. and Ahmed A.; "New tetra-Schiff bases as efficient photostabilizers for poly (vinyl chloride)". Molecules, 22, 1506, 2017. 


\section{Al-Nahrain Journal of Science}

ANJS, Vol.24 (3), September, 2021, pp. 23-29

[2] El-Hiti G.A.; Alotaibi M.H.; Ahmed A.A.; Hamad B.A.; Ahmed D.S.; Ahmed A.; Hashim H. and Yousif E.; "The Morphology and Performance of Poly (Vinyl Chloride) Containing Melamine Schiff Bases against Ultraviolet Light". Molecules 24, 803, 2019.

[3] Shaalan N.; Laftah N.; El-Hiti G.A.; Alotaibi M.H.; Muslih R.; Ahmed D.S. and Yousif E.; "Poly (vinyl Chloride) Photostabilization in the Presence of Schiff Bases Containing a Thiadiazole Moiety". Molecules, 23, 913, 2018.

[4] Al-Mashhadani M. H.; Ahmed D. S.; Adil H.; Ahmed A.; Thamer H.; Hamad B. A.; Abdallh M.; Ahmed A.; Bufaroosha M.; Mohammed S. A.; Salih N.; Yusop R. M. and Yousif E.; "A quantitative spectroscopic study of the bleaching phenomena in photo-stabilized formulations containing PVC exposed to outdoor conditions". Materials Today: Proceedings, 42, 26862692, 2021.

[5] Watheq B.; Yousif E.; Al-Mashhadani M.H.; Mohammed A.; Ahmed D.S.; Kadhom M. and Jawad, A.H.; "A Surface Morphological Study, Poly (Vinyl Chloride) Photo-Stabilizers Utilizing Ibuprofen Tin Complexes against Ultraviolet Radiation". Surfaces, 3, 579-593, 2020.

[6] Ghazi D.; El-Hiti G.A.; Yousif E.; Ahmed D.S. and Alotaibi M.H.; "The effect of ultraviolet irradiation on the physicochemical properties of poly (vinyl Chloride) films containing organotin (IV) complexes as photostabilizers". Molecules, 23, 254, 2018.

[7] Hadi A.G.; Yousif E.; El-Hiti G.A.; Ahmed D.S.; Jawad K.; Alotaibi M.H. and Hashim H.; "Long-Term Effect of Ultraviolet Irradiation on Poly (vinyl chloride) Films Containing Naproxen Diorganotin (IV) Complexes". Molecules, 24, 2396, 2019.

[8] Ahmed D.S.; El-Hiti G.A.; Yousif E. and Hameed A.S.; "Polyphosphates as Inhibitors for Poly (vinyl Chloride) Photodegradation". Molecules, 22, 1849, 2017.

[9] Yang P.; Yan J.; Sun H.; Fan H.; Chen Y.; Wang F. and Bi Shi B. Novel Environmentally Sustainable Cardanol-based Plasticizer Covalently Bound to PVC via Click Chemistry: Synthesis and Properties. RSC Adv.; 5, 16980-16985, 2015.

[10] Sakata Y.; Uddin M.A.; Koizumi K. and Murata K.; "Thermal degradation of polyethylene mixed with poly (vinyl chloride) and poly (ethyleneterephthalate)". J. Polym. Degrad. Stab. 53, 111-117, 1996.

[11] Miranda R.; Yang J.; Roy C. and Vasile C.; "Vacuum pyrolysis of PVC I. Kinetic study". J. Polym. Degrad. Stab. 64, 127-144, 1999.

[12] Marcilla A. and Beltra'n M.; "Effect of the plasticizer concentration and heating rate on the thermal decomposition behaviour of PVC plastisols. Kinetic analysis". J. Polym. Degrad. Stab. 53, 1-10, 1998.

[13]Blazso M. and Jakab E.; "Effect of metals, metal oxides, and carboxylates on the thermal decomposition processes of poly (vinyl chloride)". J. Anal. Appl. Pyrol. 49, 125-143, 1999.

[14]El-Hiti G.; Ahmed D.; Yousif E.; Alotaibi M.; Satar H. and Ahmed A.; "Influence of polyphosphates on the physicochemical properties of poly (vinyl chloride) after irradiation with ultraviolet light". Polymers 12, 193, 2020.

[15] McNeill I, Memetea L. and Colea W.J.; "A study of the products of PVC thermal degradation". J. Polym. Degrad. Stab.; 49, 181-191, 1995.

[16] Kaminsky W. and Kim J.-S.; "Pyrolysis of mixed plastics into aromatics". J. Anal. Appl. Pyrol.; 51, 127134, 1999.

[17] Ahmed A.; Al-Mashhadani M. H.; Ahmed D. S.; Ahmed A. A.; Yousif E. and Yusop R. M.; "Preparation of Polymeric films containing Schiff base as UV-Absorber with Good Resistance against UVPhotoaging". Biointerface Research in Applied Chemistry, 11, 12743-12749, 2021.

[18] Ahmed A.; Abdallh M.; Al-Mashhadani M. H.; Ahmed D. S.; Bufaroosha M.; Jawad A. H. and Yousif E.; "Environmental Stability of Poly (Vinyl Chloride) Modified by Schiff's Base under Exposure to UV". Biointerface Research in Applied Chemistry, 11, 13465 - 13473, 2021.

[19] Hadi A.G.; Jawad K.; El-Hiti G.A.; Alotaibi M.H.; Ahmed A.A.; Ahmed D.S. and Yousif E. "Photostabilization of Poly (vinyl chloride) by Organotin (IV) Compounds against Photodegradation". Molecules, 24, 3557, 2019.

[20]Fadhil Z.; Adil H.; Alsayed R.; Al-Mashhadani M. H.; Jawad A. H.; Ahmed D. S. and Yousif E.; "Poly (Vinyl Chloride) Containing Gynostemma Pentaphyllum as a Photostabilizer". Materials Science Forum, 1021, 251259, 2021.

[21]Al-Mashhadani M. H.; Thamer H.; Adil H.; Ahmed A.; Ahmed D. S.; Bufaroosha M.; Jawad A. H. and Yousif E.; "Environmental and morphological behavior of polystyrene films containing Schiff base moiety". Materials Today: Proceedings, 42, 26932699, 2021.

[22] Ghazi D.; Yousif E.; Ahmed D.S.; Thamer H.; Noaman R.; Hussien N.J.; Yusop R.M. and Jawad A.H.; "Photo-Physical Studies of PVC Mixed with Organotin (IV) Complexes". ANJS, 22(3), 1-7, 2019.

[23] Yousif E.; Ahmed D.S.; Ahmed A.A.; Hameed A.S.; Yusop R.M.; Redwan A. and Mohammed S.A.; "Experimental Relationships between Surface Roughness, Irradiation Time and Photodecomposition Rate Constant of PVC Films Doped by Polyphosphates". Science Letters, 12, 2018.

[24] Ahmed D.S.; El-Hiti G.A.; Hashim H.; Noaman R.; Hameed A.S. and Yousif E.; "Physical and morphological properties of poly (vinyl chloride) films upon irradiation in the presence of tetra schiff bases as photostabilizers". Arab Journal of Physical Chemistry. 5, 1-6, 2018. 


\section{Al-Nahrain Journal of Science}

ANJS, Vol.24 (3), September, 2021, pp. 23-29

[25] Khalaf M.; Fadhil Z.; Al-Mashhadani M. H.; Abdallh M.; Bufaroosha M.; Majeed A.; Salih N. and Yousif E.; "PVC Films Performance Stabilized by Dibutyltin (IV) Complex for Sustainable Environment". Journal of Physics: Conference Series, 1664, 2020.

[26] Mohammed S.A.; Najim L.H.; Al-Mashhadani M.H.; Ismael M.; Hamad B.A.; Noaman R.; Ibraheem H.; Ahmed D.S. and Yousif E.; "Morphological and Photodecomposition Rate Constant Study of PVC Films Doped with Sulfadiazine Tin (IV) Complexes". Science Letters, 14, 88-96, 2020.

[27] Gleeson B.; Claffey J.; Ertler D.; Hogan M.; MüllerBunz H.; Paradisi F.; Wallis D. and Tacke M.; "Novel organotin antibacterial and anticancer drugs". Polyhedron, 273619-3624, 2008.

[28] Kucklick J. R. and Ellisor M. D.; "A review of organotin contamination in arctic and subarctic regions". Emerg Contam, 5150-156, 2019.

[29] Burgess R. H.; "Manufacture and Processing of PVC". Applied Science Publishers, xi-xii, 1982.

[30] Carroll W. F.; Johnson R. W.; Moore S. S. and Paradis R. A.; "Applied Plastics Engineering Handbook". Elsevier, 61-76, 2011.

[31] Titow W. T.; "PVC Technology". $4^{\text {th }}$ Ed.; Elsevier, pp. 207-208, 1984.

[32] Ahmed D. S.; Ibrahim F. M.; Bufaroosha M.; AlMashhadani M. H.; Jawad A. H.; Yusop R. M.; Salih N.; Mohammed S. A. and Yousif E.; "Polyphosphates as thermal stabilizers for poly (vinyl chloride)". Materials Today: Proceedings, 42, 2680-2685, 2021.

[33] Nass L. I. and Heiberger C. A.; "Encyclopedia of PVC". Marcel Dekker, $2^{\text {nd }}$ Ed.; p. 397, 1986.

[34] Akovali G.; "Plastic materials: polyvinyl chloride (PVC)". Woodhead Publishing Limited, pp. 23-53, 2012.

[35] Cadogan D. F. and Howick C. J.; "Plasticizers. In Ullmann's Encyclopedia of Industrial Chemistry". Wiley-VCH: Weinheim, Germany, 2000.

[36] Gao A. X.; Bolt J. D. and Feng A. A.; "Role of titanium dioxide pigments in outdoor weathering of rigid PVC". Plast. Rubber Compos.; 37, 397-402, 2008.

[37]Chai R. D. and Zhang J.; "Synergistic effect of hindered amine light stabilizers/ultraviolet absorbers on the polyvinyl chloride/powder nitrile rubber blends during photodegradation". Polym. Eng. Sci.; 53, 1760$1769,2013$.

[38] Karayıldırım T.; Yanık J.; Yüksel M.; Sağlam M. and Haussmann M.; "Degradation of PVC containing mixtures in the presence of $\mathrm{HCl}$ fixators". J. Polym. Environ.; 13, 365-379, 2005.

[39] Ahmed A. A.; Al-mashhadani M. H.; Hashim H.; Ahmed D. S. and Yousif E.; "Morphological, Color Impact and Spectroscopic Studies of New Schiff Base Derived From 1,2,4-Triazole Ring, Prog". Color Colorants Coat.; 14, 27-34, 2021.

[40] Wypych G.; "PVC Formulary". $2^{\text {nd }}$ Ed.; ChemTec, pp. $1-3,2015$.
[41] Yousif E. and Hasan A.; "Photostabilization of poly (vinyl chloride)-Still on the run". Journal of Taibah University for Science, 9, 421-448, 2015.

[42] Mohamed N. A.; Yassin A. A.; Khalil Kh. D. and Sabaa M. W.; "Organic thermal stabilizers for rigid poly (vinyl chloride) I. Barbituric and thiobarbituric acids". Polym. Degrad. Stab.; 70, 5-10, 2000.

[43]Porta M. and Zumeta, E.; "Implementing the Stockholm treaty on persistent organic pollutants". Occup. Environ. Med.; 59, 651-652, 2002.

[44] Grossman R. F.; "Mixed metal vinyl stabilizer synergism. II: Reactions with zinc replacing cadmium". J. Vinyl Addit. Technol.; 12, 142-145, 1990.

[45]Li D.; Xie L.; Fu M.; Zhang J.; Indrawirawan S.; Zhang Y. and Tang S.; "Synergistic effects of lanthanum-pentaerythritol alkoxide with zinc stearates and with beta-diketone on the thermal stability of poly(vinyl chloride)". Polym. Degd. Stab.; 114, 52-59, 2015.

[46]Fu M.; Li D.; Liu H.; Ai H.; Zhang Y. and Zhang L.; "Synergistic effects of zinc-mannitol alkoxide with calcium/zinc stearates and with $\beta$-diketone on thermal stability of rigid poly (vinyl chloride" J. Polym. Res.; 23, 13, 2016.

[47] Wolf R. and Kaul B. L.; "Plastics, Additives. In Ullmann's Encyclopedia of Industrial Chemistry". Wiley-VCH: Weinheim, Germany, 2000.

[48] Bufaroosha M.; Salih N.; Hadi A. G.; Ahmed D. S.; Al-mashhadani M. H. and Yousif E.; "The Effect of UV Aging on the Structure of PVC in the Presence of Organotin (IV) Compounds". ANJS, 23 (2020) 57-61.

[49] Ahmed D. S.; El-Hiti G. A.; Yousif E. and Hameed A. S.; "Polyphosphates as inhibitors for poly (vinyl chloride) photodegradation". Molecules, 22, 1849, 2017. 